\title{
Gastroesophageal reflux during anaesthesia
}

L. Illing MB ChB FRCPC, P.G. Duncan MD FRCPC,

R. Yip MD FRCPC

While the number of patients at risk for vomiting and aspiration has been reported to be high, the incidence of clinically important pulmonary aspiration is low. We sought to define the incidence of gastroesophageal reflux (GER) and to correlate this with the clinical variables of obesity, history of oesophagitis, bucking and changes in body position. Continuous oesophageal pH measurement was used to determine the frequency of gastroesophageal reflux in 44 patients having general anaesthesia for elective surgical procedures. Acid reflux to a $\mathrm{pH}$ value of less than four occurred in seven patients (15.9\%) during anaesthesia. This was associated temporally with straining on the endotracheal tube in six subjects (13.6\%). We conclude that traditional risk factors are not always predictive of those patients at risk of regurgitation and aspiration.

L'incidence actualle d'aspiration pulmonaire d'importance clinique est faible malgré le nombre imposant de patients présumés à risque de vomissements et d'aspiration. Nous avons tenté de déterminer l'incidence du reflux gastro-oesophagien (GER) et d'évaluer sa corrélation avec les variables cliniques suivantes : obsésité, histoire d'oesophagite, toux ("bucking 》) et changement de position corporelle. Des mesures continues du pH oesophagien ont été utilisées afin de déterminer la fréquence du reflux gastro-oesophagien chez 44 patients subissant une anesthésie générale pour une intervention chirurgicale non urgente. On a obsrevé un reflux acide avec un pH de moins de 4 chez sept patients (15,9\%) pendant l'anesthésie. Ce reflux survenait simultanément à un effort de rejet du tube endotrachéal chez six sujets $(13,6 \%)$. En conclusion, les facteurs de risque traditionnels ne suffisent pas toujours pour prédire quels patients sont en danger de régurgitation et d'aspiration.

\section{Key words}

COMPLICATIONS: aspiration;

GASTROINTESTINAL TRACT: gastroesophageal reflux.

From the Department of Anaesthesia, Royal University

Hospital, Saskatoon, Saskatchewan, S7N 0XO.

Address correspondence to: Dr. L. Illing.

Accepted for publication 12th January, 1992.
Regurgitation and aspiration of gastric contents remain important concerns during the administration of general anaesthesia. The frequency of regurgitation and aspiration has been determined during anaesthesia by examination of pharyngeal or tracheal aspirates for acidity or ingested dyes. These studies have indicated a 4 to $26 \%$ incidence of regurgitation during anaesthesia. ${ }^{2-6} \mathrm{An}$ increase in the frequency of regurgitation was associated with nasogastric and endotracheal tube use and certain types of positioning. ${ }^{3,4}$ In addition, emergency laparoscopy was associated with regurgitation. ${ }^{6}$ Detectable aspiration occurred in 50 to $76 \%$ of these cases. In contrast, the incidence of clinically important aspiration derived from large anaesthesia surveys varies from $1.4 / 10,000$ to $6.4 / 10,000$ anaesthetics. ${ }^{7-9}$ Clearly the volume and acidity of the aspirate plays a role.

In this study continuous oesophageal $\mathrm{pH}$ monitoring was used to detect the frequency of gastroesophageal reflux (GER) in awake and anaesthetised subjects. We further tested whether head-down positioning, increased intra-abdominal pressure, obesity or history of symptomatic oesophageal reflux was correlated with the occurrence of GER during anaesthesia.

\section{Methods}

Following institutional approval and informed consent, a total of $\mathbf{4 4}$ adult patients scheduled for elective surgery were enrolled in the study (Table I).

All patients were interviewed before anaesthesia for symptoms of reflux. Weight and height were recorded. The patients were divided into two groups: Group A, consisting of 16 patients were studied in the awake and anaesthetized states. The mean time that these patients were monitored was $64.7 \pm 10.9$ (SEM) awake and 81.7 $\pm 9.3 \mathrm{~min}$ whilst anaesthetized. Group B was composed of a further 28 patients who were studied only after induction of anaesthesia. The mean times of monitoring of patients in the Trendelenburg and horizontal positions were $20.1 \pm$ 3.8 and $27.4 \pm 6.2 \mathrm{~min}$ respectively.

In Group A, fasting patients were requested to swallow a nasally placed bipolar glass $\mathrm{pH}$ probe (Ingold Messtechnik AG stomach probe) approximately one hour before induction of anaesthesia. After placement in the stomach, indicated by a $\mathrm{pH}$ of $<4$, the patients were placed in a head-down position of about $10^{\circ}$ with left lateral tilt and 
TABLE I Demographic data (SEM)

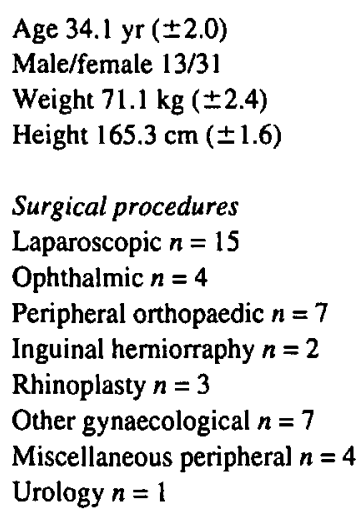

the probe was withdrawn slowly. In all patients an abrupt $\mathrm{pH}$ change occurred to a value $>4$. The probe was then withdrawn a further $5 \mathrm{~cm}$ and taped securely to the nose. ${ }^{18}$ In addition, when a second probe became available, a unipolar antimony $\mathrm{pH}$ probe was placed in the pharynx of the next eight patients after induction of anaesthesia. Both $\mathrm{pH}$ probes were calibrated against solutions of standardized buffers at $\mathrm{pH}$ of 4 and 7 before each set of measurements. There was no noticeable drift in the $\mathrm{pH}$ measurements as evidenced by repeat calibration with the two reference buffers at the end of each study period. Measurements of $\mathrm{pH}$ were made every five seconds and stored by a portable pH monitor (PROXIMA $2.1 \mathrm{pH}$ Monitor). Important perioperative events were recorded as observed by the investigator. These included bucking, straining, tracheal intubation, positional change or increased intra-abdominal pressure. After surgery these events could be correlated with episodes of reflux. The probes were removed in the PAR following recovery from anaesthesia.

In Group B the method of probe placement was identical except that both probes were placed shortly after induction of anaesthesia. Episodes of reflux were compared in the horizontal and Trendelenburg positions. The influence of raised intra-abdominal pressure on gastroesophageal reflux (GER) was studied in 15 female patients who underwent laparoscopy. The probes were removed in the $O R$ following extubation when the patients were able to respond to verbal commands as demonstrated by eye opening.

Patients were considered to have a history of oesophageal reflux $(n=5)$ if symptoms of retrosternal discomfort related to meals or to the supine position or an acidic taste in the mouth were present at least once weekly.

Patients whose body mass index (BMI) was greater than 30 (BMI $=$ mass $[\mathrm{kg}] \div$ height $^{2}\left[\mathrm{~m}^{2}\right]$ were considered to be obese $^{20}(n=7)$.
TABLE II Percentage of patients in Group A demonstrating $\mathrm{pH}$ episodes of less than $4(n=16)$.

Awake $12.5\left(2^{*}\right)$

Induction 0

Maintenance 6.3\% (1†)

Straining 25\% (4)

Recovery room $18.8 \%\left(3^{*}\right)$

Numbers of patients shown in parentheses.

*Emesis occurred in one patient during $\mathrm{pH}$ change.

$\dagger$ Associated with extubation.

Volatile anaesthetic agents supplemented with nitrous oxide and narcotics were used. The use of muscle relaxants was left to the discretion of attending anaesthetist. Anticholinergics were only used as a component of relaxant reversal. Drugs affecting gastric $\mathrm{pH}$ were avoided. An oesophageal stethoscope or nasogastric tube was never used. The surgeon was asked to limit electrocautery to short bursts as this affected the $\mathrm{pH}$ measurements; information recorded during these times was discarded.

A significant reflux episode was defined as an abrupt decrease in $\mathrm{pH}$ to a value $<4$. Statistical analysis was performed using Yates corrected Chi squared analysis and Student $t$ tests with each patient serving as his or her own control. Significance was set at $P$ value $\leq 0.05$.

\section{Results}

Spontaneous GER occurred in two of the 16 patients monitored while awake, one of whom subsequently had lower oesophageal reflux while anaesthetized (Table II). These patients did not have a history of symptomatic oesophageal reflux.

A decrease in lower oesophageal $\mathrm{pH}$, from 6.02 to 5.47 , followed induction of anaesthesia $(P<0.01)$. This returned approximately to baseline values during emergence from anaesthesia in the majority of cases (Figure).

Of the 44 patients studied, GER occurred during anaesthesia in seven subjects $(15.9 \%)$. This was associated with bucking or coughing on the tube in six subjects. Two of these patients had reflux to the level of the pharynx as detected by a $\mathrm{pH}$ change to a value less than four units. However, of 23 patients who bucked, only six had detectable GER (Tables II and III).

Episodes of reflux were not detected during position changes after exclusion of GER associated with bucking (Table III). No GER was demonstrated during abdominal insufflation in patients undergoing laparoscopy.

History of symptomatic oesophagitis predicted reflux during anaesthesia in only two patients. In contrast, four of 39 patients without a history of reflux oesophagitis subsequently developed GER during anaesthesia.

Of seven obese patients one had GER during anaesthesia compared with five of 37 non-obese subjects. 


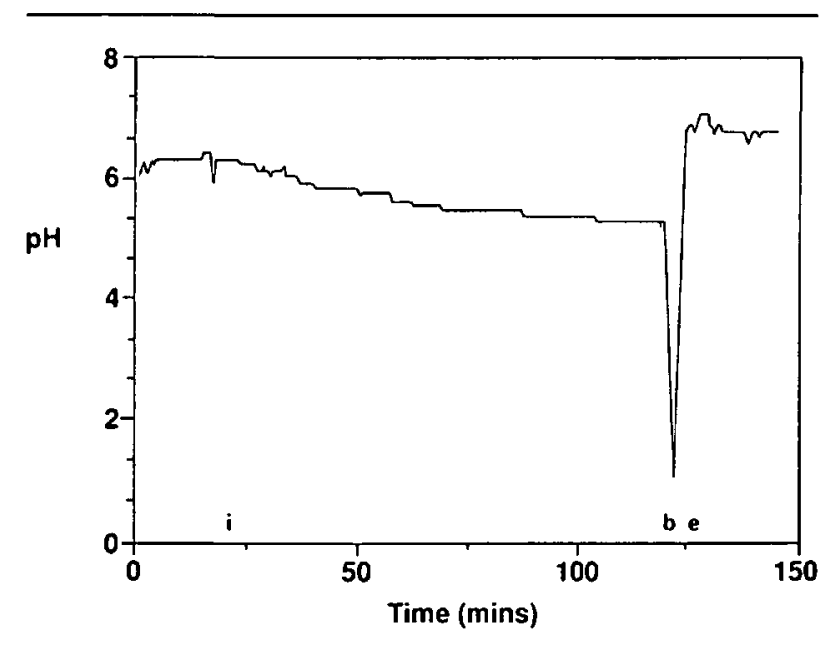

FIGURE Patient D: Herniorrhaphy. (— pH probe; i-induction; b-coughing; e-extubation).

The associations of body habitus, Trendelenburg position, increased intra-abdominal pressure, reflux oesophagitis with GER during general anaesthesia failed to achieve statistical significance utilising Yates' corrected Chi squared analysis.

\section{Discussion}

Lower oesophageal $\mathrm{pH}$ monitoring first came into routine clinical use as a method of evaluating symptoms suggestive of reflux oesophagitis. Ambulatory pH monitoring is now considered to be the most specific and sensitive method of diagnosing reflux oesophagitis. Unfortunately the presence or absence of reflux as detected by a $\mathrm{pH}$ probe is not sufficient, by itself, to diagnose pathological reflux. Indeed, normal individuals will have detectable reflux, termed physiological reflux, during which lower oesophageal $\mathrm{pH}$ is $<4$ during a $24 \mathrm{hr}$ period, especially during deglutition. ${ }^{21} \mathrm{~A}$ scoring system incorporating the percentage of time the lower oesophageal $\mathrm{pH}$ is $<4$, the total number of reflux episodes, the number of episodes longer than five minutes and the time of the longest reflux episode was therefore developed to allow better discrimination between pathological and physiological reflux. ${ }^{10}$

The validity of this scoring system in defining the risk of significant reflux during anaesthesia is questionable, particularly since even a single episode of reflux may result in life-threatening damage to the respiratory system. However, the risk of clinically important aspiration is low as indicated by several perioperative morbidity studies. ${ }^{7-9}$ Clearly there is more to aspiration risk than the presence or absence of reflux. Volume and acidity of the gastric contents and airway protection are equally important. ${ }^{1}$ Since our $\mathrm{pH}$ monitor only detects the hydrogen ion concentration of the refluxed fluid we cannot comment on
TABLE III Percentage of patients in Group B demonstrating pH changes of less than $4(n=28)$

Supine $7.1 \%(2 *)$

Trendelenburg 0

Numbers of patients shown in parentheses.

*Associated with straining on both occasions.

the aspiration risk. We can measure only one of the many factors felt to be important in the pathogenesis of clinically important aspiration.

Recently, continuous $\mathrm{pH}$ monitoring has been used in ICU patients whose tracheas had been intubated. It was felt that pharyngeal reflux was important in the pathogenesis of laryngeal damage. ${ }^{11}$ It has also been used in a patient with a hiatus hernia during mask anaesthesia for the purpose of detecting pharyngeal reflux. ${ }^{12}$

We considered that any episodes of $\mathrm{pH}$ change detected proximal to the lower oesophageal sphincter would be important, since this is considered to be an important barrier preventing pharyngeal reflux during anaesthesia. ${ }^{1}$

The decrease in lower oesophageal $\mathrm{pH}$ occurring shortly after induction of anaesthesia is interesting but probably does not represent true reflux as the $\left[\mathrm{H}^{+}\right]$does not approach gastric values $(\mathrm{pH}<4)$. Clearance of residual acid from the lower oesophagus is dependent on swallowed saliva. ${ }^{13}$ Swallowing decreases from 70 times a minute during fasting, waking hours to less than seven times an hour during normal sleep. ${ }^{4}$ Anaesthesia has been shown to depress oesophageal motility. ${ }^{15}$ Therefore, it is likely that this represents failure of the swallowing mechanism to maintain the lower oesophageal-gastric $\mathrm{pH}$ gradient during anaesthesia.

Our observations indicate that GER and pharyngeal reflux commonly occur during emergence from anaesthesia and during bucking on the endotracheal tube. Attempts to prevent regurgitation of gastric contents by providing cricothyroid pressure during induction of anaesthesia will not prevent this possibility from occurring later, during the maintenance and emergence phases of anaesthesia. Residual quantities of anaesthetic drugs may depress airway reflexes in spite of attempts to perform an awake extubation. ${ }^{22}$ In addition, the effects of nonparticulate antacid prophylaxis may not persist to the end of the anaesthetic. The anaesthetist should be aware that reflux and aspiration may occur at any time during the anaesthesia.

In view of the small number of patients in each of the risk groups it is possible that our failure to show a difference between the groups may be a type II error. Our observations do show, however, that reflux is reasonably common in low-risk individuals.

Two previous studies using continuous $\mathrm{pH}$ monitoring 
have failed to demonstrate reflux during anaesthesia. In a study by Kofke et al., ${ }^{16}$ no episodes of pharyngeal reflux were detected in 20 patients during mask anaesthesia. However, these patients' tracheas were not intubated and they were, therefore, unlikely to cough during the anaesthetic. The small size of the study meant that the $95 \%$ confidence interval for the incidence of reflux was between 0 and $17 \%$ as acknowledged by the authors. In an attempt to correlate residual gastric volume with regurgitation Hardy et al. ${ }^{17}$ measured oesophageal $\mathrm{pH}$ continuously in 100 anaesthetized patients whose tracheas had been intubated. No episodes of reflux were detected in spite of excessive residual gastric volumes present in 46 patients. However, monitoring was restricted to the period prior to surgical incision. In our series this was a period of low regurgitation risk as reflux was either detected during a period of light anaesthesia midway through surgery or, more frequently, during emergence prior to extubation. In a third study, ${ }^{18}$ Roberts et al. utilising similar experimental conditions to our own, detected a single episode of reflux in two of 63 patients during anaesthesia. Both patients hiccoughed during induction of anaesthesia.

In conclusion, we have demonstrated reflux into the lower oesophagus and pharynx of anaesthetized patients using a continuous $\mathrm{pH}$ monitor. This occurred in $13.6 \%$ and $4.5 \%$ of cases respectively and tended to develop shortly before tracheal extubation in the majority of cases. Although the relationship of this $\mathrm{pH}$ change to the incidence of clinically important pulmonary aspiration remains to be determined, anaesthetists need to be vigilant of this preventable source of perioperative morbidity and mortality. Indeed, in the recent Confidential Enquiry into Maternal Deaths ${ }^{19}$ aspiration of gastric contents caused 11 of 31 deaths directly associated with anaesthesia. The failure to correlate $\mathrm{pH}$ change with position, increased abdominal pressure, or obesity suggests that the traditional descriptors of patients at risk may not be valid. Our results suggest that physical effects modifying the gradient between the abdominal cavities such as coughing or airway obstruction may be more commonly associated with GER. If supported by other investigations such an hypothesis would suggest that the risk of regurgitation of gastric contents will be more a function of how the anaesthetic is conducted than of the characteristics of individual patients.

\section{References}

1 Hardy $J F$. Large volume gastroesophageal reflux: a rationale for risk reduction in the perioperative period. Can J Anaesth 1988; 35: 162-73.

2 Berson W, Adriani J. "Silent" regurgitation and aspiration during anesthesia. Anesthesiology 1954; 15: 644-9.
3 Blitt CD, Guttman HL, Cohen DD, Weisman H, Dillon $J B$. Silent regurgitation and aspiration during general anaesthesia. Anesth Analg 1970; 49: 707-13.

4 Turndorf $H$, Rodis $I D$, Clark TS. "Silent" regurgitation during general anesthesia. Anesth Analg 1974; 53: 700-3.

5 Satiani B, Bonner JT, Stone HH. Factors influencing intraoperative gastric regurgitation. Arch Surg 1978; 113 : 721-3.

6 Carisson $C$, Islander $G$. Silent gastropharyngeal regurgitation during anesthesia. Anesth Analg 1981; 60: 655-7.

7 Tiret L, Desmonts JM, Hatton F Vourc' $h$ G. Complications associated with anaesthesia - a prospective survey in France. Can Anaesth Soc J 1986; 33: 336-44.

8 Cohen MM, Duncan PG, Pope WDB, Wolkenstein C. A survey of 112,000 anaesthetics at one teaching hospital. Can Anaesth Soc J 1986; 33: 22-31.

9 Olsson GL, Hallen B, Hambraeus-Jonzen $K$. Aspiration during anaesthesia: a computer aided study. Acta Anaesthesiol Scand 1986; 30: 84-92.

10 Johnson LF, DeMeester TR. Twenty-four-hour pH monitoring of the distal esophagus. Am J Gastroenterol 1974; 62: 325-32.

11 Gaynor EB. Gastroesophageal reflux as an etiologic factor in laryngeal complications of intubation. Laryngoscope 1988; 98: 972-9.

12 Kofke WA, Thayer $T$. Induction of thiopental anaesthesia without tracheal intubation in a patient with hiatal hernia: use of esophageal pH monitoring. Anesthesiology 1990; 72: 950-1.

13 Helm JF, Dodds WJ, Pelc LR, Palmer DW, Hogan WJ, Teeter $B C$. Effect of esophageal emptying and saliva on clearance of acid from the esophagus. N Engl J Med 1984; 310: 284-8.

14 Nelson JB, Castell DO. Esophageal motility disorders. Disease-a-Month June 1988.

15 Evans $J M$, Wise CC, Davies WL. Lower oesophageal contractility: a new monitor of anaesthesia. Lancet 1984; 1 : $1151-4$.

16 Kofke UUA, Fasano M, Keamy MF, Derr JA. Continuous hypopharyngeal pH via mask. Anesthesiology 1987; 67: 434-6.

17 Hardy JF, Lepage Y, Bonneville-Chouinard N. Occurrence of gastroesophageal reflux on induction of anaesthesia does not correlate with the volume of gastric contents. Can J Anaesth 1990; 37: 502-8.

18 Roberts CJ, Goodman NW. Gastro-oesophageal reflux during elective laparoscopy. Anaesthesia 1990; 45: 1009-11.

19 Tomkins J, Turnbill A, Robson G, et al. Report on confidential enquiries into maternal deaths in England and Wales 1976-1978. London: Her Majesty's Stationary Office. 
20 Burton BT, Foster WR, Hirsch J, Van Itallie TB. Health implications of obesity: an NIH Consensus Development Conference. Int J Obes 1985; 9: 155-70.

21 Boesby S. Gastro-oesophageal acid reflux and sphincter pressure in normal human subjects. Scand J Gastroenterol 1975; 10: 731-6.

22 Burgess GE, Cooper JR, Marino RJ, et al. Laryngeal competence after tracheal extubation. Anesthesiology 1979; 51: 73-7. 